\title{
Identification and prioritization of hazardous material transportation strategies using DEA method
}

\author{
Saeid Esmaeili $^{a^{*}}$, Mahdi Hosseinpour ${ }^{a}$, Khashayar Sheikhi ${ }^{a}$ and Nader Naderi ${ }^{b}$
}

${ }^{a}$ M.A. Student of MBA, Kermanshah Science and Research Branch, Islamic Azad University, Kermanshah, Iran ${ }^{b}$ Member of Entrepreneurship Department, Razi University, Kermanshah, Iran

\begin{tabular}{|c|c|}
\hline ART I CLE I NFO & A B S T R A C T \\
\hline $\begin{array}{l}\text { Article history: } \\
\text { Received June 20, } 2012 \\
\text { Received in Revised form } \\
\text { August, 20, } 2012 \\
\text { Accepted 25 August } 2012 \\
\text { Available online } \\
\text { 3 September } 2012 \\
\text { Keywords: } \\
\text { Hazardous material } \\
\text { Data envelopment analysis } \\
\text { SWOT }\end{array}$ & $\begin{array}{l}\text { Development of industries needs expansion of public transportation and, consequently, heavy } \\
\text { transportation increases hazardous and dangerous transportation too. Therefore, we need to } \\
\text { consider some strategies to reduce bad effects of transportation of hazardous materials such as } \\
\text { road accidents. Strength, Weakness, Opportunity and Treats (SWOT) analysis is an applicable } \\
\text { method for designing strategies in this area. However, SWOT analysis does not provide specific } \\
\text { strategies and it does not consider the efficiency and performance of each strategy. Applying a } \\
\text { hybrid method of analyzing the strategies and their performance evaluation help decision } \\
\text { makers select the best strategies based on the current limitations. In this paper, different } \\
\text { strategies for hazardous transportation risk reduction are designed and relative efficiencies of all } \\
\text { alternatives are compared using DEA method. The proposed model of this paper uses three } \\
\text { inputs including implementation costs, operation and maintenance cost and operational and four } \\
\text { outputs including accident rate reduction, fuel consumption reduction, employment rate } \\
\text { increment and deaths number reduction. The results of the implementation using seven different } \\
\text { strategies have yielded two important strategies including continuous improvement of vehicle } \\
\text { standards, driving skills, transportation system quality, and loading methods and expansion of } \\
\text { petroleum pipe network. }\end{array}$ \\
\hline
\end{tabular}

\section{Introduction}

Hazardous material is defined as some materials that are dangerous for the life of people and environment. Researchers are categorizing hazardous materials in nine categories as follows,

\section{Gas;}

2. Flammable liquids;

\section{Non-liquid flammables;}


4. Oxidants;

5. Explosives;

6. Acid liquids;

7. Radioactive materials;

8. Toxic substances; and

9. Other hazardous materials.

These hazardous materials should be transported from one place to another in different roads like other materials. Transportation methods and adopting related strategies for these materials shipment play important role in transportation planning. There is a growing interest in planning transportation of hazardous materials anywhere in the world. Ghazinoory and Kheirkhah (2008) considered the present condition of transportation of hazardous materials in Iran and the resulting accidents. They explained that optimal condition for the general transportation system of hazardous materials was delineated with due focus on transportation risk as the main parameter. They also explained different strategies for reaching the optimal condition and the impacts of these strategies on the reduction of accidents were analyzed.

These days, hazardous materials are required in different industries such as petroleum, oil refineries, chemical and petrochemical industries, expansion of fuel needed in factories, etc. There are literally various studies focused on different aspects involved in transportation of hazardous materials. Lack of appropriate transporting roads, lack of railroads, accident rate growth in world, etc. are just some aspects of them. We can utilize different methods for studying the related ways for decreasing the accident rate and increasing the hazardous transportation safety in Iranian roads. SWOT analysis is one of these methods but despite many advantages of adopting SWOT analysis, it suffers from some shortcomings. SWOT analysis cannot measure the efficiency of each strategy and consequently cannot provide a prioritized list of strategies. In fact, SWOT analysis is a useful method for designing strategies but not a good one for ranking them. It does not help decision makers select the best strategies. To resolve this problem we may utilize a DEA method and measure the efficiency of each strategy based on defined inputs and outputs and finally ranked them based on their relative efficiencies.

There are literally different studies for adaptation of SWOT in transportation of hazardous materials. Kheirkhah et al. (2009), for instance, explained that an increase in hazardous materials transportation in Iran along with the industrial development and increase of resulted deadly accidents necessitate the development and implementation of some strategies to reduce these incidents. They also explained that SWOT analysis was an efficient method for developing strategies, however, its structural problems, including a lack of prioritizing internal and external factors and inability to consider two sided factors reducing its performance in the situations where the number of internal and external factors influencing the risk of hazardous materials was relatively high and some factors are two sided in nature are presented in the article. Fuzzy SWOT analysis is a method the use of which helps with solving these problems and is the issue of employing an effective methodology. In addition, they compared the resulted strategies of the fuzzy method with the strategies developed following SWOT in order to show the relative supremacy of the new method.

In this paper, we present an empirical study to make appropriate strategy selection for transportation of hazardous materials. The proposed model of this paper uses data envelopment analysis to consider different factors influencing various strategies and order the best efficient strategies. 


\section{Data Envelopment Analysis}

DEA is a mathematical modeling for efficiency evaluation of decision making units (DMUs) based on their common consumption of inputs and production of outputs. Charnes et al. $(1978,1994)$ are believed to be the first people who introduced the idea of measuring relative efficiencies of similar units based on different inputs/outputs. For years, DEA has been successfully implemented for various industries to setup appropriate targets (Sarkis, 1997; Ball \& Wilkinson, 2000). Fallah et al. (2011), for instance, examined DEA models for the estimation and improvement of organizational inputs and outputs in order to enhance management and decision making processes. They proposed an empirical DEA analysis on banking sector by considering several financial and non-financial inputs and outputs. The relative efficiencies of various branches of banks are analyzed in various scenarios. Ahmadkhani and Babakhania (2011) presented an empirical study to measure the relative efficiencies of training organizations using DEA method. The study used a Delphi method to determine the most important input/output factors and then gathered the actual data for all units located in an Iranian province called Zanjan. The results of the implementation of the DEA method were compared for various periods and they were analyzed. They performed the DEA implementation for two separate regions, one for the units located inside the city and the other for the units located in the rural area. The output results of both methods were compared and the results are discussed in details.

In this section, we present the problem statement of the proposed DEA method used in this paper. In a DEA method, there are normally some inputs and outputs associated with all decision-making units. Let $x_{i j}$ be the inputs for one of decision-making unit with $i=1, \ldots, m$ and $y_{r j}$ be the outputs of the same units with $r=1, \ldots, s$ and $j=1, \ldots, n$ and suppose $u_{i}$ and $v_{j}$ are the dual variables associated with $x_{i}$ and $y_{j}$, respectively. The constant return to scale DEA modeling formulation is as follows,

$\max$

$$
Z=\frac{\sum_{r=1}^{s} u_{r} y_{r} .}{\sum_{i=1}^{m} v_{i} x_{i} .}
$$

$$
\begin{array}{cc}
\text { subject to } & \frac{\sum_{r=1}^{s} u_{r} y_{r j}}{\sum_{i=1}^{m} v_{i} x_{i j}} \leq 1 . \\
X_{i j}, y_{i j \geq 0}
\end{array}
$$

Model (1) is the basic DEA, which can be solved $j$ times to determine the relative efficiencies of various units. However, since model (1) is nonlinear in structure, Charles et al. (1978) proposed a simple modification of the objective function to convert model (1) into a simple linear programming problem as follows,

$$
\begin{array}{ll}
\max & Z=\sum_{r=1}^{s} u_{r} y_{r} . \\
\text { subject to } & \frac{\sum_{r=1}^{s} u_{r} y_{r j}}{\sum_{i=1}^{m} v_{i} x_{i j}} \leq 1 .
\end{array}
$$




$$
\begin{aligned}
& \sum_{i=1}^{m} v_{i} x_{i .}=1 \\
& u_{r}, v_{i} \geq 0, \quad j=1, \ldots, n
\end{aligned}
$$

Problem (2) has been widely used for the past three decades and the results are commonly accepted as a tool for measuring the relative efficiencies of various units. There are literally different versions of DEA methods such as input or output oriented models and they are used depending on whether we have control on the output or the input parameters. DEA models have been extended when there are uncertainties associated with inputs/outputs called robust DEA. In robust DEA we consider an acceptable perturbation on each parameters and final solution will not change as long as these parameters change in the interval of uncertainties (Roghanian \& Foroughi, 2010).

\section{DEA Implementation in Hazardous Transportation}

To reduce danger of hazardous transportation, some strategies can be adopted by SWOT analysis. These strategies are listing as below:

A: Continuous improvement of vehicle standards, driving skills, transportation system quality, and loading methods,

B: Expansion of petroleum pipe network,

C: Implementing up to date technologies in hazardous transportation system,

D: Media coverage and vast broadcasting of high risk of hazardous transportation,

E: Implementation of safety management systems in hazardous transportation companies,

F: Establishing special and high skilled companies for hazardous material transporting,

G: Expansion of research based organizations for studying on hazardous transportation systems.

Seven strategies were listed. For evaluating these strategies we determined some inputs and outputs.

Determined inputs and outputs are:

\begin{tabular}{ll}
\hline Inputs & $\mathrm{C}_{1}:$ Implementation Costs \\
& $\mathrm{C}_{2}:$ Operation and Maintenance Cost \\
\hline $\mathrm{C}_{3}:$ Operational
\end{tabular}

\begin{tabular}{ll} 
Outputs & $\mathrm{B}_{1}:$ Accident Rate Reduction \\
\cline { 2 - 2 } & $\mathrm{B}_{2}:$ Fuel Consumption Reduction \\
\hline $\mathrm{B}_{3}:$ Employment Rate Increment \\
\hline $\mathrm{B}_{4}:$ Deaths number Reduction
\end{tabular}

For strategy evaluation, essential information are gleaned from different resources. Traffic officers, traffic and transportation experts, truck drivers and other related resources were selected as a confident source of information. Table 1 and 2 are showing the normalized data gathered from experts.

\section{Table1}

Data gathered as inputs

\begin{tabular}{cccc}
\hline Strategy & $\mathrm{C}_{3}$ & $\mathrm{C}_{2}$ & $\mathrm{C}_{1}$ \\
\hline $\mathrm{A}$ & 0.15 & 0.14 & 0.05 \\
$\mathrm{~B}$ & 0.20 & 0.125 & 0.17 \\
$\mathrm{C}$ & 0.18 & 0.12 & 0.08 \\
$\mathrm{D}$ & 0.03 & 0.13 & 0.1 \\
$\mathrm{E}$ & 0.05 & 0.045 & 0.12 \\
$\mathrm{~F}$ & 0.10 & 0.075 & 0.14 \\
$\mathrm{G}$ & 0.075 & 0.05 & 0.03 \\
\hline
\end{tabular}

Table 2

Data gathered as outputs

\begin{tabular}{cccc}
\hline $\mathrm{B}_{4}$ & $\mathrm{~B}_{3}$ & $\mathrm{~B}_{2}$ & $\mathrm{~B}_{1}$ \\
\hline 0.57 & 0.17 & 0.27 & 0.60 \\
0.54 & 0.44 & 0.50 & 0.32 \\
0.47 & 0.23 & 0.15 & 0.56 \\
0.36 & 0.26 & 0.15 & 0.52 \\
0.41 & 0.14 & 0.23 & 0.49 \\
0.46 & 0.50 & 0.54 & 0.40 \\
0.36 & 0.36 & 0.49 & 0.40 \\
\hline
\end{tabular}


The implementation of Eq. (2) using the inputs and outputs given in Table 1 and Table 2 yields the efficiencies for strategies A to G given in Table 3.

Table 3

The results of the relative efficiencies of seven strategies

\begin{tabular}{llllcccc}
\hline Strategy & A & B & C & D & E & F & G \\
\hline Efficiency & 1 & 1 & 0.69 & 0.88 & 0.81 & 0.93 & 0.76 \\
\hline
\end{tabular}

Based on the extracted results from the software, we prioritized the strategies by their efficiency.

$$
\text { A-B-F-D-E-G-C }
$$

This rank would help decision makers select the best strategies. In other words, the first two strategies including continuous improvement of vehicle standards, driving skills, transportation system quality, and loading methods and expansion of petroleum pipe network are the best candidates for transportation of hazardous materials. Another competitive alternative is to establish special and high skilled companies for hazardous material transportation. In addition, media coverage and vast broadcasting of high risk of hazardous transportation as well as implementation of safety management systems in hazardous transportation companies could also be considered as alternative strategies.

\section{Conclusions}

Hazardous materials are subjects of many studies and different strategies could be used for the shipment of such materials. However, it is not always easy to make appropriate selection among various alternatives. One alternative is to consider different factors influencing selection of various strategies and build a DEA method. The proposed model of this paper has implemented a DEA model to handle strategy selection. The proposed model of this paper used three inputs including implementation costs, operation and maintenance cost and operational and four outputs including accident rate reduction, fuel consumption reduction, employment rate increment and deaths number reduction. The results of the implementation using seven different strategies have yielded two important strategies including continuous improvement of vehicle standards, driving skills, transportation system quality, and loading methods and expansion of petroleum pipe network.

\section{Acknowledgment}

The authors would like to thank the anonymous referees for constructive comments on earlier version of this paper.

\section{References}

Ahmadkhani, A., \& Babakhania, M. (2011). An empirical study to measure the relative efficiencies of training organizations using data envelopment analysis. Management Science Letters, 1(2), 195-202.

Ball, R., \& Wilkinson, R. H. (2000). Measuring the performance of higher education institutions. proceedings of the thirteenth international forum of the European Association for Institutional Research. 219 - 234.

Charnes A, Cooper, W. W., Rhodes, E. (1978). Measuring the efficiency of decision making units. European Journal of the Operational Research, 2, 429-44.

Charnes A, Cooper W. W., Lewin, A., Seiford, L. M. (1994). Data envelopment analysis: theory, methodology and applications. Massachusetts: Kluwer Academic Publishers. 
Fallah, M., Aryanezhad, M. B., Najafi, S. E., \& Shahsavaripour, N. (2011). An empirical study on measuring the relative efficiency using DEA method: A case study of bank industry. Management Science Letters, 1(1), 49-56.

Ghazinoory, S. \& Kheirkhah, A.S. (2008). Transportation of hazardous materials in Iran: A strategic approach for decreasing accidents. Transport, 23(2), 104-111.

Kheirkhah, A.S., Esmailzadeh, A., \& Ghazinoory, S. (2009). Developing strategies to reduce the risk of hazardous materials transportation in Iran using the method of fuzzy SWOT analysis, Transport. 24(4), 325-332.

Roghanian, E. \& Foroughi, A. (2010). An empirical study of Iranian regional airports using robust data envelopment analysis. International Journal of Industrial Engineering Computations, 1(1), 65-72.

Sarkis, J. (1997). A comparative analysis of DEA as a discrete alternative multiple criteria decision tool. European Journal of Operational Research, 19(1), 96-109. 